университет», президент Российской ассоциации преподавателей английской литературы. Тел.: +7 (499) 246-57-12. E-mail: chernozem888@yandex.ru

Zakharov Nikolay Vladimirovich, PhD, Candidate of Philology; Director, Shakespeare Centre, Institute of Fundamental and Applied Studies, Moscow University for the Humanities; full member, International Academy of Science (Innsbruck, Austria); Academic Secretary, Shakespeare Committee, Russian Academy of Sciences. Postal address: Bldg. 6, 5 Yunosti St., 111395 Moscow, Russian Federation. Tel.: +7 (499) 374-75-95.E-mail: nikoltine@yandex.ru

Gaydin Boris Nikolaevich, Candidate of Philosophy, Head, Research Department of Digital Technologies, Institute of Fundamental and Applied Studies, Moscow University for the Humanities; Associate Member, International Academy of Science (Innsbruck, Austria). Postal address: Bldg. 6, 5 Yunosti St., 111395 Moscow, Russian Federation. Tel.: +7 (499) 374-59-30. E-mail: bngaydin@mosgu.ru

Lisovich Inna Ivanovna, Doctor of Culturology, Candidate of Philology, Professor, Department of Philosophy, Culturology and Politology, Moscow University for the Humanities. Postal address: 5 Yunosti St., 111395 Moscow, Russian Federation. Tel.: +7 (499) 374-55-11. E-mail: mag-inna@yandex.ru

Makarov Vladimir Sergeevich, Candidate of Philology, Associate Professor, Department of Germanic Philology, St. Tikhon's Orthodox University. Postal address: Bldg. 2, 9 Ilovaiskaya St., 109651 Moscow, Russian Federation. Tel.: +7 (495) 646-71-38. E-mail: mail@vmakarov.name

Shipilova Natalia Vitalievna, Candidate of Philology, Senior Lecturer, Department of Germanic Philology, St. Tikhon's Orthodox University. Postal address: Bldg. 2, 9 Ilovaiskaya St., 109651 Moscow, Russian Federation. Tel.: +7 (495) 646-71-38. E-mail: mezo-ra@mail.ru

Chernozemova Elena Nikolaevna, Doctor of Philology, Professor, Department of World Literature, Moscow State University of Education (MSPU); President, Russian Teachers of English Literature Association. Tel.: +7 (499) 246-57-12.E-mail: chernozem888@yandex.ru

DOI 10.17805/zpu.2018.4.17

\title{
Кристофер Марло, понимаемый как протосоциолог
}

\author{
В. А. ЛУКОВ \\ МОСКОВСКИЙ ГУМАНИТАРНЫЙ УНИВЕРСИТЕТ
}

Есть основания считать К. Марло протосоциологом, т. е. лицом, которое задолго до становления научной социологии увидело человека в общественных связях, поняло его место в социальном мире как на макро-, так и на микроуровне. Он, разумеется, нес идеи понимания социальности человека, которые его окружали в елизаветинскую эпоху и которые, что называется, носились в воздухе. Иначе не могло быть у молодого драматурга, погибшего в 29 лет. Но этим не умаляется его вклад в понимание человека как общественного существа. Было бы натяжкой видеть в К. Марло социолога, пытавшегося показать устройство английского общества XVI в. Но видеть в нем, как и в “университетских умах» его времени, и в У. Шекспире, протосоциологическую линию полезно и для развития исторической социологии, и для лучшего понимания и конструирования тех версий субъектной социологии, для которых важно стремление человека преобразовывать окружающий мир, в какие бы времена это ни происходило. 
В основе статьи текст доклада автора на Первой Всероссийской научной конференции «Кристофер Марло и его творчество в русской и мировой культуре: междисциплинарный взгляд», которая прошла в Москве 22-23 июня 2018 г.

Ключевые слова: Кристофер Марло; протосоциолог; “университетские умы»; английское общество XVI в.; история английской литературы; Англия

\section{ВВЕАЕНИЕ}

\ ристофер Марло, английский поэт и драматург времен Елизаветы I Тюдор (мно- гими признаваемый второй фигурой в культуре того времени вслед за Шекспиром), родился за 275 лет до того, как в 4-м томе «Курса позитивной философии» француза Огюста Конта впервые прозвучало слово «социология» (Comte, 1839: 252). Он не был знаком с законом трех стадий, выведенным Контом для общества и человека, был далек от классового подхода Карла Маркса к капиталистическому обществу, ничего не слыхал о спорах конца XIX в. по поводу статуса социологии в кругу других наук о человеке и не знал, что «социологизм» Эмиля Аюркгейма означал установление для социологии своего особого предмета и своего метода, не догадывался даже о том, что вкладывал Макс Вебер в свою трактовку «понимающей» социологии, не участвовал в непримиримой вражде сторонников количественных и качественных методов, а потом в кризисе парсоновской модели общественной системы, постмодернистской критике социологии как таковой и ее последующем возрождении в европейской, американской, российской общественной мысли...

Чаще всего Марло привлекает внимание исследователей и любителей как человек, удивительным образом сочетавший в себе поэта и шпиона (Honan, 2005). П. Хонан, например, показывает, как юный колледжист Марло становится курьером и агентом елизаветинского Тайного совета. Вполне вероятно, что он был завербован «гением шпионажа» Фрэнсисом Уолсингемом, возглавлявшим английскую разведку времен Елизаветы I (Hutchinson, 2007). В путанице его любовных связей, богемности, опасного вольнодумства, таланта драматурга и поэта, бытовой непокорности, с одной стороны, и шпионских удач - с другой, загадочной и особо привлекательной предстает его гибель в 29 лет в пьяной драке от рук его друзей - всех как один елизаветинских шпионов, так что среди исследователей укрепилась версия, что вооруженная потасовка была подстроена (Кuriyama, 2002). Каскад тайн необыкновенно интересен, подобен хорошо закрученному детективу XXI в. и отодвигает в тень некоторые черты поэта, на которые бы следовало посмотреть даже при недостатке подтвержденных документами фактов его жизни и творчества.

Есть, например, основания считать Марло если не социологом в современном смысле слова, то протосоциологом, т. е. лицом, которое задолго до становления социологии как научной дисциплины увидел человека в общественных связях, поняло его место в социальном мире как на макро- так и на микроуровне. Он, разумеется, нес идеи понимания социальности человека, которые его окружали в елизаветинскую эпоху и которые, что называется, носились в воздухе. Иначе не могло быть у молодого драматурга. Но этим не умаляется его вклад в понимание человека как общественного существа. Применение тезаурусного подхода, который в современной социологии показал свою эвристичность как один из вариантов субъектно-ориентированной теории общества (Ауков, 2018abcd), в этом случае дает аргументы для такого понимания Марло.

Что это за аргументы? Во-первых, субъект (а им может быть отдельный человек, группа, социальная общность какого угодно большого размера и т. А.) не только при- 
нимает окружающий мир как регулирующий его деятельность и устанавливающий Аля него границы возможного, но и как полигон творчества, создания нового, разнообразного применения своих способностей. В этом ракурсе значение имеет не столько сам этот окружающий мир сам по себе, сколько картина мира, составляющая ядро тезауруса - тех когнитивных средств, которые каждому субъекту нужны, чтобы ориентироваться в среде своего существования и деятельности и чтобы творить новое (Ауков В., Ауков Вл., 2008; Погорский, 2012; Кузнецова, Ауков В., 2009; Кузнецова, 2012). Во-вторых, знание в тезаурусе не строится по структуре наук, какими они сложились в Новое время в европейском обществе, ее магистральный путь - от своего к чужому при блокировании чуждого. В исследованиях культурных имплементаций в русскую литературу (Захаров, 2008) и т. А. тезаурусный подход показал, что научный склад мышления не только не всеобщ, но и ограничивает человека в его понимании мира и представлении о его свойствах, прошлом и перспективах. В-третьих, понятие о культурных константах, разработанное в рамках тезаурусного подхода, позволяет в «вечных» образах и сюжетах (Гайдин, 2009), в культурно-коммуникативных формулах (Завьявова, 2017) увидеть основания Аля длительного сохранения средств сохранения и воспроизводства культур, взаимодействия культур разных народов, а в конечном счете быть одним из несущих стержней субъектной культурологии (Ауков Вл., 2008). В окружении таких положений Марло и может быть понят как протосоциолог.

Несколько обстоятельств способствовали представлению Марло о социальности человека.

Неоднократно указывается, что Марло в подростковом возрасте до 1580 г., т. е. до 16 лет, изучал в местной школе латынь, основы греческого языка, а также пение и стихосложение. Это обычный путь для посещавшего школу, но как это отразится в социализационной траектории сына сапожника, в этом возрасте еще неизвестно. Очевидно, что в «Трагической истории доктора Фауста» (конец 1588 или начало 1589 г.) знание латыни сквозит в репликах Фауста, Мефистофеля, иных персонажей. Можно догадываться, что учеба в грамматической школе, но в еще большей мере учеба в колледже Тела Христова Кембриджского университета, обозначенного успешным завершением молодым Марло сначала бакалавриата (в 20 лет), а потом магистратуры (в 23 года), определили его владение латынью как языком науки того времени.

Надо учитывать круг Марло в аспекте происхождения, вовлечения в дела елизаветинской эпохи и т. А., разнообразие этого круга стало особо актуально после переезда Марло в ник Кембриджа (St John's College), сошелся с Марло после своего приезда в Мондон в 1588 г. (Nicholl, 1984) и даже вместе с ним писал трагедию о Аидоне. Томас Кид, с которым на паях Марло снимал комнату, был сыном нотариуса. В то же время друг Марло Томас Уолсингем относился к числу придворных, его дядя, упомянутый выше, сэр Фрэнсис был министром Елизаветы I, членом Тайного совета. Отметим, что Томас был третьим сыном важного землевладельца в Кенте сэра Томаса Уолсингема (1526-1584) и внуком сэра Эдмунда Уолсингема, придворного Генриха VIII, а затем лейтенанта лондонского Тауэра. Марло входил в кружок вольнодумцев, собиравшихся в доме сэра Уолтера Рэли, а надо учитывать, что Рэли, будучи на 10-12 лет старше Марло, к этому времени был не только английским придворным, что, возможно, было только для аристократа, но и государственным деятелем, поэтом и писателем, историком, а еще и моряком, прославившимся, по существу, пиратскими нападениями на 
испанский флот (за что был в 1585 г. удостоен рыцарства), одним из первых колонизаторов Северной Америки. Марло, богемный образ жизни которого подчеркивается исследователями, мало считался с социальным статусом окружавших его лиц, с барьерами и границами, отделявшими статусы в сословном обществе. По одним сведениям, последняя пирушка Марло (или политическое убийство) была в кабаке, по другим - в наемном загородном доме, но этим разночтением лишь подтверждается, что оно не имеет значения, и Марло одинаково хорошо себя чувствовал в социально не схожих условиях.

Рэли был явно богатым человеком. Нэш описывается совершенно нищим, его описания путешествия в Венецию - сплошь выдумка: у него не было средств на такой вояж. Но Марло и здесь - по имущественному положению и его видимым признакам не проводил границы: его тезаурус (ориентационный комплекс) был способен к такого рода совмещениям. Большее значение имело сходство возрастов, когда еще не было связанных с возрастом закрепленных границ социализационных траекторий, имевших влияние на судьбы людей значительно позже (обязательное начальное образование, поступление в вуз, срочная служба в армии и т. А.). Характерно, что Нэш был на три года моложе Марло, Томас Уолсингем на три года старше, «университетские умы» Роберт Грин и Томас Кид на шесть лет старше, Уильям Шекспир того же, что и Марло, года рождения и т. А. Иначе говоря, все это молодежь того времени, желающая прославиться, добиться чего-то значимого в своей жизни и применяющая для этого уже накопленные знания (обычно в бакалавриате и магистратуре Кембриджа или Оксфорда), энергию и талант. Когорта как социологическое понятие (люди одного возраста с небольшими отклонениями в один-два года, что сейчас определяет различие социокультурных поколений, но в XVI в. не имело значения как социальный факт) к кругу Марло вряд ли применимо.

Полем приложения молодыми и образованными людьми знаний, энергии и таланта не становилась придворная жизнь, построенная на сословной иерархии и принятых правилах, но зато его можно было искать в театрах, постоянно работавших в Аондоне с 1576 г. (т. е. когда Марло и Шекспиру было по 12 лет), а до того - в представлениях, дававшихся в гостиницах. Эта сторона повседневности больших городов давала широкий простор для воображения, но идущего с двух сторон: от драматургов, ориентированных на публику, и от публики с ее картинами мира, которым надо было соответствовать. Свобода театральных подмостков (в пределах, принимаемых публикой и не нарушающих общественные устои) давала пищу для экспериментов молодых и грамотных выпускников английских университетов: отсутствие имени драматурга в сообщении о представлении (афишах, где они уже появились), возможность заимствовать сюжеты и обстоятельства действия из книг, а также и возможность использовать сколько угодно материала других драматургов, в том числе друзей, стиль, композицию, особенности стиха и т. А. Фактически критерий успеха определялся отношением зрителей, публики. Вот почему Фауст у Марло говорит по-латыни, что называется, через каждую фразу: зритель не обязан был это понимать, но ученый в его мнении это человек, способный главные свои мысли выражать «по-научному», а значит - полатыни. У Марло во всех его пьесах полно героев греческой и римской Античности. Но и у других авторов того времени то же самое. Конечно, это следы университетского образования, но и зрители, публика настроены на такие имена и события, принимают и понимают их. Марло, как и драматурги его времени, включая и «университетские умы», не заботился о точности фактов. Его Тамерлан - скифский пастух, но 
ничего подобного в биографии подлинного Тамерлана нет. Смерть Эдуарда II переделана Марло в сравнении с хроникой Ральфа Холиншеда 1586 г., из которой заимствован сюжет трагедии об английском короле. Нередко автор шел вслед за популярными версиями, легендами, принятыми публикой английских театров, ему исторические факты были не нужны. Это напоминает современную «альтернативную историю», но мотивы, которые двигали Марло и присущи современным представителям «альтернативной истории», принципиально различаются.

В микросоциологии Марло интересен тем, что круг его контактов широк и он может представить английское общество своего времени в этой обширной перспективе. Многое идет от жизни Марло, хорошо изученной и дающей определенный тип город-

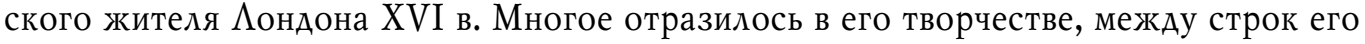
трагедий, если их читать в этом ключе. Но вряд ли надо искать у Марло реминисценции с особенностями его жизни, например с местами его учебы. Они, конечно, могут найтись в «Трагической истории доктора Фауста» и других произведениях. Но театр того времени не дает декораций колледжа, мы достраиваем мир, который имеет три Авери и помост для любой пьесы.

В макросоциологии небезынтересны сетевые отношения Марло с «университетскими умами», кругом секретных агентов и т. А. на фоне иерархических отношений власти, церкви, всей общественной жизни Англии XVI в. Интересны и представления англичан той эпохи о картине мира. Геоцентрическая система Птолемея пока не потеснена книгой Коперника, хотя она уже появилась. Великий закон аналогии (приписываемый Гермесу Трисмегисту и гласивший: «То, что находится внизу, соответствует тому, что пребывает вверху; и то, что пребывает вверху, соответствует тому, что находится внизу, чтобы осуществить чудеса единой вещи»), сквозит в каждом произведении Марло. Нас скорее тут интересует не он сам, а мировоззрение англичан его времени.

Но более всего феномен Марло привлекателен для социологии молодежи, где сочетание дикости и новационности рассматривается как основание биосоциологии молодежи $(\Lambda$ уков, 2013, 2018c). Оно массово проявляется на стадии перехода к информационному обществу, но оно могло быть менее заметным и тем не менее существенным фактором общественного развития и раньше, что подтверждает жизнь и творчество Кристофера Марло.

Было бы натяжкой видеть в Марло социолога, пытавшегося показать устройство английского общества XVI в. в категориях современной социологии, в представлениях о его социальной структуре, социальных процессах, социальных институтах. «Pеконструкция» здесь на базе случайно совпадающих высказываний и домыслов неуместна. Но видеть в нем, как и в «университетских умах» его времени, и в Шекспире, протосоциологическую линию полезно и для развития исторической социологии, и для лучшего понимания и конструирования тех версий субъектной социологии, для которых важно стремление человека преобразовывать окружающий мир, в какие бы времена это ни происходило.

СПИСОК АИТЕРАТУРЫ

Гайдин, Б. Н. (2009) Вечные образы как константы культуры (интерпретация «гамлетовского вопроса») : дис. ... канд. филос. наук. М. 194 с.

Завьялова, Н. А. (2017) Культурно-коммуникативные формулы в рамках тезаурусного подхода // Знание. Понимание. Умение. № 3. С. 152-162. 
Захаров, Н. В. (2008) Шекспиризм русской классической литературы: тезаурусный анализ. М. : ИзА-во Моск. гуманит. ун-та. 320 с.

Кузнецова, Т. Ф., Ауков, Вл. А. (2009) Культурная картина мира в свете тенденций развития культурологии // Вестник Международной академии наук (Русская секция). № 1. С. 66-69.

Кузнецова, Т. Ф. (2012) Культурная картина мира: теоретические проблемы. М. : ГИТР. $250 \mathrm{c}$.

Ауков, В. А. (2013) Биосоциология молодежи: теоретико-методологические основания. М. : ИзА-во Моск. гуманит. ун-та. 430 с.

Иуков, В. А. (2018а) Тезаурусная социология : в 4 т. : монография. М. : ИзА-во Моск. гуманит. ун-та. Т. 1.608 с.

Иуков, В. А. (2018b) Тезаурусная социология : в 4 т. : монография. М. : ИзА-во Моск. гуманит. ун-та. Т. 2. 576 с.

Иуков, В. А. (2018c) Тезаурусная социология : в 4 т. : монография. М. : Изд-во Моск. гуманит. ун-та. Т. 3.608 с.

Иуков, В. А. (2018d) Тезаурусная социология : в 4 т. : монография. М. : Изд-во Моск. гуманит. ун-та. Т. 4.640 с.

Ауков, В. А., Ауков, Вл. А. (2008) Тезаурусы: Субъектная организация гуманитарного знания : науч. монография. М. : ИзА-во Нац. ин-та бизнеса. 784 с.

Ауков, Вл. А. (2008) Культурология объектная и субъектная // Знание. Понимание. Умение. № 1. C. 72-79.

Погорский, Э. К. (2012) Картина мира // Знание. Понимание. Умение. № 4. С. 322-323.

Comte, A. (1839) Cours de philosophie positive. Paris. T. 4. 736 p.

Nicholl, Ch. (1984) A cup of news. The life of Thomas Nash. Boston : Routledge \& Kegan Paul. ix, $342 \mathrm{p}$.

Hutchinson, R. (2007) Elizabeth's Spymaster: Francis Walsingham and the secret war that saved England Phoenix. N. Y. : Thomas Dunne Books ; St. Martin's Press. 399 p.

Honan, P. (2005) Christopher Marlowe: Poet and spy. N. Y. : Oxford University Press Inc. 438 p.

Kuriyama, C. Br. (2002) Christopher Marlowe: A Renaissance life. N. Y. : Cornell University Press. 255 p.

Аата поступления: 10.08.2018 2.

\section{CHRISTOPHER MARLOWE SEEN AS A PROTO-SOCIOLOGIST \\ V. A. LUKOV \\ MOSCOW UNIVERSITY FOR THE HUMANITIES}

There are reasons to consider C. Marlowe a proto-sociologist, that is an individual who, long before the establishment of scientific sociology, saw man within social relationships, realized his role in the social world both on the macro-, and on the micro-level. It goes without saying that he conveyed the ideas of the sociality of man which were common in the Elizabethan era, and which were in the air, so to speak. It could not have been otherwise for a young playwright who passed away at 29. But his contribution to the understanding of man as a social entity is in no way lessened by this fact. It would be far-fetched to consider C. Marlowe as a sociologist who tried to demonstrate the structure of the 16th century English society. But to recognize his proto-sociological pattern similar to both the University wits of his time, and W. Shakespeare, would be useful for the development of historical sociology, for better understanding and construction of versions of subjective sociology which rely on the man's endeavor to transform the environment, no matter the historical period.

The article is based on the author's speech at the First All-Russian Scientific Conference "Christopher Marlowe and His Oeuvre in Russian and World Culture: an Interdisciplinary Viewpoint» which was held in Moscow on 22-23 June 2018.

Keywords: Christopher Marlowe; proto-sociologist; «university wits»; 16th century English society; history of English literature; England 


\section{REFERENCES}

Gaidin, B. N. (2009) Vechnye obrazy kak konstanty kul'tury (interpretatsiia "gamletovskogo voprosa») : Dis. ... Candidate of Philology. Moscow. 194 p. (In Russ.).

Zav'ialova, N. A. (2017) Kul'turno-kommunikativnye formuly v ramkakh tezaurusnogo podkhoda. Znanie. Ponimanie. Umenie, no. 3, pp. 152-162. (In Russ.).

Zakharov, N. V. (2008) Shekspirizm russkoi klassicheskoi literatury: tezaurusnyi analiz. Moscow, Izd-vo Mosk. gumanit. un-ta. 320 p. (In Russ.).

Kuznetsova, T. F. and Lukov, Vl. A. (2009) Kul'turnaia kartina mira v svete tendentsii razvitiia kul'turologii. Vestnik Mezhdunarodnoi akademii nauk (Russkaia sektsiia), no. 1, pp. 66-69. (In Russ.).

Kuznetsova, T. F. (2012) Kul'turnaia kartina mira: teoreticheskie problemy. Moscow, GITR. 250 p. (In Russ.).

Lukov, V. A. (2013) Biosotsiologiia molodezhi: teoretiko-metodologicheskie osnovaniia. Moscow, Izd-vo Mosk. gumanit. un-ta. 430 p. (In Russ.).

Lukov, V. A. (2018a) Tezaurusnaia sotsiologiia: in 4 vol. Moscow, Izd-vo Mosk. gumanit. un-ta. Vol. 1.608 p. (In Russ.).

Lukov, V. A. (2018b) Tezaurusnaia sotsiologiia: in 4 vol. Moscow, Izd-vo Mosk. gumanit. un-ta. Vol. 2.576 p. (In Russ.).

Lukov, V. A. (2018c) Tezaurusnaia sotsiologiia: in 4 vol. Moscow, Izd-vo Mosk. gumanit. un-ta. Vol. 3.608 p. (In Russ.).

Lukov, V. A. (2018d) Tezaurusnaia sotsiologiia: in 4 vol. Moscow, Izd-vo Mosk. gumanit. un-ta. Vol. 4.640 p. (In Russ.).

Lukov, V. A. and Lukov, Vl. A. (2008) Tezaurusy: Sub'ektnaia organizatsiia gumanitarnogo znaniia. Moscow, Izd-vo Nats. in-ta biznesa. 784 p. (In Russ.).

Lukov, Vl. A. (2008) Kul'turologiia ob»ektnaia i sub'ektnaia. Znanie. Ponimanie. Umenie, no. 1, pp. 72-79. (In Russ.).

Pogorskii, E. K. (2012) Kartina mira. Znanie. Ponimanie. Umenie, no. 4, pp. 322-323. (In Russ.).

Comte, A. (1839) Cours de philosophie positive. Paris. Vol. 4. 736 p.

Nicholl, Ch. (1984) A cup of news. The life of Thomas Nash. Boston, Routledge \& Kegan Paul. ix, 342 p.

Hutchinson, R. (2007) Elizabeth's Spymaster: Francis Walsingham and the secret war that saved England Phoenix. New York, Thomas Dunne Books; St. Martin's Press. 399 p.

Honan, P. (2005) Christopher Marlowe: Poet and spy. New York, Oxford University Press Inc. $438 \mathrm{p}$.

Kuriyama, C. Br. (2002) Christopher Marlowe: A Renaissance life. New York, Cornell University Press. 255 p.

Submission date: 10.08 .2018$.

Ауков Валерий Андреевич - доктор философских наук, профессор, директор Центра социального проектирования и тезаурусных концепций Института фундаментальных и прикладных исследований Московского гуманитарного университета, заслуженный деятель науки Российской Федерации. Адрес: 111395, Россия, г. Москва, ул. Юности, д. 5. Тел.: +7 (499) 374-75-95. Эл. aApec: v-lukov@list.ru

Lukov Valeriy Andreyevich, Doctor of Philosophy, Professor, Director, Centre for Social Planning and Thesaurus Conceptions, Institute of Fundamental and Applied Studies, Moscow University for the Humanities; Honoured Scientist of the Russian Federation. Postal address: 5, Yunosti St., Moscow, Russian Federation, 111395. Tel.: +7 (499) 374-75-95. E-mail: v-lukov@list.ru 